\title{
Multilevel determinants of teenage childbearing in sub-Saharan Africa in the context of HIV/AIDS
}

Monica A. Magadi (School of Education and Social Sciences, University of Hull)

\begin{abstract}
This paper examined national variations and multilevel determinants of teenage childbearing in sub-Saharan Africa (SSA) in the context of HIV/AIDS using data from recent Demographic and Health Surveys conducted in 29 countries of SSA. Results showed significant community and national variations in teenage childbearing, partly explained by socio-economic and HIV/AIDS context. At community level, lower HIV/AIDS stigma, higher wealth and female education were associated with lower teenage childbearing. However, national socio-economic status had an intricate relationship with teenage childbearing. Higher national GDP per-capita was generally associated with higher teenage childbearing, and this relationship was stronger in lower HIV prevalence countries.
\end{abstract}

Key words: teenage childbearing; contextual determinants; HIV/AIDS context; sub-Saharan Africa; multilevel logistic regression; national variations; Demographic and Health Surveys

\section{Highlights}

- Higher community wealth and female education are associated with lower teenage childbearing

- Evidence of higher teenage childbearing in communities of higher HIV prevalence, testing coverage or HIV/AIDS stigma

- Relationship between national GDP per-capita and teenage childbearing moderated by HIV prevalence

- Positive association between national GDP per-capita and teenage childbearing stronger in lower HIV prevalence countries 


\section{Introduction}

Teenage childbearing remains a global concern given its contribution to overall or unwanted fertility (Christofides et al, 2015; Okigbo and Speizer, 2015; United Nations, 2015), socioeconomic impact (Bissell, 2000; Paranjothy et al, 2009), and association with adverse maternal and newborn health outcomes (Magadi, 2006; Chen et al, 2007; Ganchimeg et al, 2014; Woog et al, 2015). Indeed, the cost-saving of preventing unwanted childbearing is greatest among adolescents (UNFPA, 2014). This is of particular relevance in sub-Saharan Africa (SSA), the region with the highest rates of teenage childbearing that is often associated with socio-economic disadvantage (Odejimi and Bellingham-Young, 2014) and compounded with HIV/AIDS epidemic (Christofides et al, 2014). The relationship between teenage childbearing and socio-economic status is a complex one, with pathways of the relationship being in either direction - socio-economic disadvantage being a consequence and at the same time a determinant of teenage childbearing. This paper focuses on the latter.

Despite SSA having the highest levels of teenage pregnancy and HIV prevalence in the world, comprehensive empirical research on contextual determinants of teenage pregnancy or link with HIV/AIDS epidemic is scarce. The need to prevent both early pregnancy and HIV infection among young people in SSA has been well recognised, and further research has been recommended to examine the relationship between related adolescent behaviours, risks and health outcomes (Kothari et al., 2012). Recent cross-national comparative analysis of teenage childbearing patterns across countries have largely focused on high-income countries (Sedgh et al, 2015), and extensive work has been undertaken on appropriate adolescent interventions in these settings. However, little empirical evidence is available in 
SSA to guide adolescent programmatic interventions in the region (Phillips and Mbizvo, 2016).

The determinants of teenage childbearing are diverse, ranging from background socioeconomic and cultural factors (UNFPA, 2005; Were, 2007; Prathan et al, 2015) to more proximate demographic and sexual behaviour factors (Vundule et al, 2001; Okigbo and Speizer, 2015). Findings on socio-economic determinants consistently suggest greater vulnerability among disadvantaged and deprived groups both at individual and neighbourhood levels (Brewster 1994; UNFPA 2005; UNFPA 2014; Prathan et al, 2015). According to UNFPA (2005), girls from the lowest socio-economic groups are three times more likely than their economically better off peers to give birth in adolescence and have twice as many children.

An international study of adolescent pregnancy in urban disadvantaged settings across five cities (Baltimore, Johannesburg, Ibadan, New Delhi and Shanghai) highlighted the need for Pregnancy risk to be understood within the specific context where adolescents reside, with particular attention to neighbourhood-level factors (Brahmbhatt, et al., 2014). Within SSA, the need to view teenage pregnancies and associated risks within the broader socioeconomic and socio-cultural context/environment in which the adolescents live has been emphasized (Were 2007; Brahmbhatt,et al., 2014), but empirical studies on teenage pregnancy and childbearing focusing on context are limited.

Individual and household-level determinants of teenage childbearing in the developing countries are relatively well established, but contextual determinants are less well understood. A recent systematic review identified socio-economic (Limited education, low - . 
socioeconomic position, living in a rural area), cultural (belonging to an ethnic and religious minority group), and demographic or sexual behaviour factors (insufficient access to and non-use of contraception, early sexual initiation and early marriage) as important risk factors for pregnancy among adolescents in in low-income and lower middle-income countries (Pradhan et al, 2015). In particular, strong empirical evidence exists on the importance of secondary education at individual level (Gupta and Mahy, 2003).

Most research attention on neighbourhood context of teenage childbearing has focused largely on socio-economic environment, including area deprivation, GDP per capita, female education/literacy and contraceptive prevalence. An important aspect of societal context in adolescent childbearing that has received little or no research attention, despite particular relevance in SSA, relates to HIV/AIDS context. First, teenage pregnancy and HIV infection (especially in SSA where heterosexual contact is the main mode of transmission) share a common risk factor - unprotected sex (Clark, 2004). However, the interplay between unprotected sex with HIV and fertility risk can be complex, depending on the nature of relationship - committed relationships being associated with higher pregnancy risk while casual relationships are associated with greater HIV risk. In a recent study in Kenya, Duflo et al (2014) observed that HIV prevention curricula that focus on an abstinence-until-marriage message did not reduce teenage pregnancy as it led to an increase in early marriage. Therefore, it is important to understand how HIV context may influence teenage pregnancy and childbearing in SSA settings where high incidence of both HIV and teenage childbearing are of particular concern. Furthermore, an understanding of national variations and the extent to which observed patterns are consistent across SSA countries will help better inform international efforts aimed at addressing the problem of teenage pregnancy in the context of HIV in the SSA region. 
This study aims to improve understanding of multilevel (community and country) determinants of teenage childbearing in sub-Saharan Africa in the context of HIV/AIDS. Specific objectives are to:

(i) examine community and national determinants of teenage childbearing in SSA, with particular reference to contextual HIV/AIDS - related factors and socioeconomic context; and

(ii) explore national variations in teenage childbearing across countries of SSA.

\section{Multilevel determinants of teenage childbearing in SSA in the context of HIV/AIDS: conceptual considerations and study hypotheses}

\section{The multilevel determinants}

The social and economic determinants of teenage childbearing may operate at individual, family, community and national level (Cherry et al., 2009). The importance of social context in influencing reproductive health outcomes in the developing countries has long been recognized (Pebley et al., 1996; Duncan et al, 1998). A number of studies underscore the importance of neighbourhood and social context in influencing adolescent sexual/ reproductive behaviour (Brewster et al 1993; Brewster, 1994; Diamond et al, 1999; McCulloch, 2001).

Contextual factors operating at the lower local level (i.e community) and at broader societal or national level (i.e country) are likely to impact on teenage sexual/reproductive health differently. At the local/community level, prevailing attitudes/stigma/prejudice and resource availability are likely to be more directly linked to accessibility and use of 
reproductive health services by young people. Denno et al. (2015) underscored the importance of community support/acceptance of adolescent sexual and reproductive health services. At national level, resources and relevant policies and laws would determine service provision/ availability. Auerbach et al. (2006) highlight the importance of social arrangements, institutions, laws, policies and customs in influencing the ability of individuals to engage in protective behaviours. Therefore, for most contextual determinants of teenage childbearing, we would expect to have national-level effects, beyond any community-level effects which may include both socio-economic and HIV/AIDS-related determinants.

\section{Socio-economic context}

Important Socio-economic context include income/wealth and education/literacy both at local community level and at national level. Available studies, mainly in the developed countries, suggest that unfavourable socio-economic conditions at local area or community level contribute to high teen birth rates (McCulloch, 2001; Penman-Aguilar et al., 2013). In the United States, South and Baumer (2001) had attributed higher teenage childbearing in poor communities to pregnant adolescents in deprived neighbourhoods being less likely than those in wealthier communities to voluntarily terminate a pregnancy, rather than to higher pregnancy rates in poor communities.

Limited evidence available from the developing countries include a recent analysis of World Bank data between 2008 and 2010 for 51 African countries which identified female literacy as the best predictor, while healthcare expenditure and GDP per capita also had a significant inverse relationship (based on bivariate correlations) with teenage pregnancy (Odejimi and Bellingham-Young, 2014). Other studies in SSA, not specific to adolescents, have identified community's socio-cultural environment and wealth status as important

\section{$5 \mid$}


predictors of women's sexual behaviour, contraceptive and other reproductive health outcomes (Stephenson et al., 2007; Uthman and Kongnyuy, 2008).

Although most available literature suggest an inverse relationship between socio-economic development and teenage childbearing, this relationship is unlikely to be straight forward. It has been hypothesized that more money equates with increased opportunities for paid and extramarital sex and that '...at national level, a higher income and development may result in urban congestion, more migrant workers and more room for transactional sex (Rodrigo and Rajapakse, $2010: 10$ ) which in the absence of contraception is likely to lead to increased teenage pregnancy and childbearing.

\section{HIV/AIDS context}

In most SSA settings, the importance of societal context in shaping teenage reproductive health experiences is further complicated by the HIV/AIDS epidemic. For example, the apparent relationship between socio-economic development and teenage childbearing outlined above is likely to vary by HIV/AIDS context. Furthermore, HIV prevention strategies, including the $A B C$ campaign, that have been adopted in various SSA countries to curb the spread of HIV (Barnett and Parkhurst 2005; Parikh, 2007; Coates, et al, 2008) are likely to influence teenage childbearing and HIV risk in different ways. While delayed sexual debut or abstinence $(A)$ and use of condom (C) will reduce risk of both HIV and pregnancy, being faithful (B) or reduction of multiple casual partners may not necessarily reduce teenage pregnancy risk, especially if this leads to committed relationships or early marriage (Duflo et al., 2014) in the absence of contraceptive use. The strategies adopted to prevent HIV transmission in different settings recognize that individual action is not shaped by immediate life conditions alone, but by the community and wider societal/structural factors as well (Gupta et al, 2008; UNAIDS, 2010; Vu et al, 2017). These may include a number of 
contextual HIV/AIDS-related factors, including HIV prevalence, comprehensive knowledge of how HIV is transmitted/ ways to prevent transmission, HIV/AIDS stigma, and availability of HIV treatment or testing services at both community and national level. For instance, comprehensive HIV/AIDS knowledge in a community may facilitate greater condom acceptance and use while HIV/AIDS stigma or misconception may hinder acceptance/use (Allen and Heald, 2004).

Besides HIV prevention strategies, the rapidly changing HIV treatment scenario in SSA has important reproductive health implications, including teenage childbearing. HIV-positive status, once viewed as a life sentence and acted more as a deterrent to early initiation or unsafe sexual practices (Tenkorang and Maticka-Tyndale, 2014), is increasingly viewed as a long-term chronic condition, as accessibility of HIV testing and treatment services become more widespread. Availability of such services will depend on national policies/strategies to combat HIV/AIDS epidemic which is in turn likely to be influenced by the national HIV/AIDS burden and available national resources.

\section{Research hypotheses}

Based on the preceding conceptual and theoretical considerations, we formulate the following hypotheses:

(i) socio-economic environment at both local/community and national level is likely to have a significant effect on teenage childbearing in SSA;

(ii) National and community-level HIV/AIDS-related factors are likely to be important determinants of teenage childbearing in SSA;

(iii) Contextual determinants at community and national levels are likely to differ; and 
(iv) The effect of socio-economic development on teenage childbearing in SSA is likely to vary by HIV/AIDS context.

\section{Data and Methods}

\section{The Data}

This study is based on secondary analysis of recent data from the international Demographic and Health Surveys (DHS) programme. All countries where the DHS has included HIV testing in standard DHS or in AIDS Indicator Surveys (AIS) were targeted for inclusion in the study. Since 2001, the DHS has included HIV testing on nationally representative samples of men and women of reproductive age in 31 countries of sub-Saharan Africa (SSA). All, except two countries (Benin and Equatorial Guinea) for which data were not available for further analysis, were included in this study (i.e. a total of 29 countries). Our analysis sample was restricted to the women sample in the most recent DHS with HIV test data during the period 2006-2014, focusing on teenagers aged 15-19 years. For countries where HIV test data are available from multiple DHS, only the most recent DHS was used. The female teenage sample aged 15-19 ranges from a low of 540 in Sao Tome to a high of 5040 in Malawi, with a total of 70506 cases in the 29 countries. A summary of the data included in the analysis is presented in Table 1.

(TABLE 1 ABOUT HERE)

The DHS and AIS adopt a multi-stage sampling design which involves random selection of primary sampling units (clusters), followed with a systematic selection of households from which survey respondents are drawn. In a number of recent DHSs, survey respondents were asked to voluntarily provide blood samples for HIV testing. The recent DHSs that incorporate HIV testing provide a unique opportunity for population-based studies of factors associated 8 I 
with the HIV/AIDS epidemic, allowing for anonymous linkage of HIV test data to individuallevel survey data with background socio-economic and demographic/health characteristics. The DHS HIV testing protocols endure strict ethical review procedures providing for informed/voluntary testing of adults of reproductive age. A detailed description of the DHS/AIS survey design is available elsewhere (ICF Macro, 2010). The standardised nature of the DHS and AIS sampling design and data collection instruments allows for pooling of data across countries to enable an examination of cross-national variations.

\section{Study variables}

The outcome variable (i.e dependent variable) is teenage pregnancy or birth while the main explanatory variables include community/cluster and national determinants of teenage childbearing. Individual or household level exposure variables or confounders are controlled for in the analysis.

Dependent variable: Teenage childbearing. We recognize that the definition of the term teenage childbearing may vary across countries and cultures - while industrialised countries normally use age (or legal age of adulthood) to define teenage pregnancy, the developing countries tend to consider teenage pregnancy as a concern mostly when the teenage girl is unmarried (Cherry et al, 2009). In this study we have used age to define teenage childbearing, whether this is within or outside marriage, given the adverse socio-economic and health consequences of early childbearing in most SSA settings where a large proportion of teenage births occur within marriage. Thus, our outcome variable takes the value of ' 1 ' if a 15-19 years old teenager reported having ever had a birth or pregnant at the time of the survey, and a value of ' 0 ' otherwise. We prefer to use the term teenage childbearing rather than teenage pregnancy since reliable data on pregnancies that do not result in live births due to abortions or miscarriages are lacking in most of SSA settings 
where restrictive abortion laws means that most induced abortions are clandestine and go unreported.

Explanatory variables include: (i) community-level HIV/AIDS-related factors (HIV prevalence, HIV testing coverage, HIV/AIDS awareness and stigma), average female education, average wealth and urban/rural residence; and (ii) national-level HIV/AIDS-related factors (HIV prevalence, HIV testing coverage, HIV/AIDS awareness and stigma), female education and GDP per capita. In addition to the explanatory variables listed above, a number of individual or household characteristics including background socio-economic and socio-cultural factors (educational attainment, household wealth, household size, gender of household head and religion) perceived to be associated with teenage childbearing based on existing literature are controlled for in the analysis. Furthermore, two proximate factors that are more directly linked to teenage childbearing (i.e. early sex and teen marriage) were considered in a separate model to examine the extent to which observed patterns were explained by early sexual debut or early marriage among specific sub-groups.

Furthermore, all multivariate models adjusted for potential key exposures or confounders relating to current age and year of survey. It is important to control for age at time of survey since the risk of teenage childbearing is directly linked to the duration of exposure. For example, 19-year-olds would have been exposed throughout their teenage years while 15year-olds would have been exposed for a much shorter period. Preliminary analysis (not presented) was undertaken to explore potential variations in the relationship between socio-economic status and teenage childbearing by age, to explore the expectation that richer women may be having children nearer 19 years than poorer women. Contrary to this expectation, observed patterns suggested higher odds of teenage pregnancy among poor 
compared to non-poor women among 19 year olds than 15 year olds. An assessment of homogeneity of odds ratios suggested a significant difference in odds ratios across age, necessitating consideration of age* wealth interaction among the individual/household level covariates controlled for in the analysis. Also, controlling for year of survey was considered necessary to adjust for any potential effect of trends on national variations as the period in which the surveys were conducted ranges from 2006 to 2014.

All contextual community-level factors and most national factors were derived from individual-level data based on mean indices or the proportion of the respondents in the cluster or country with characteristics of interest. Besides data on national GDP per capita that were derived from World Bank estimates (World Bank, 2017), all other contextual measures were aggregated from individual-level data. A description of study variables included in the analysis is given in Annex (i) while summary national data are presented in Annex (ii).

\section{Methods of Analysis}

The analysis includes: (i) descriptive analysis of levels of teenage childbearing and proximate factors (early sex and teenage marriage) across countries in SSA; and (ii) multivariate analysis based on multilevel logistic regression. The option of using survival analysis instead of logistic regression was considered to adequately handle censured cases, but a decision was made to use the latter, taking into account duration of exposure (i.e age at time of the survey), the focus of the paper being on teenage childbearing rather than timing of first birth. 
The multilevel analysis takes into consideration the hierarchical data structure with individuals/households (level 1) nested within clusters/communities (level 2) which are in turn nested within countries (level 3). The DHS clusters are equivalent to primary sampling units, typically census enumeration areas, electoral zones or villages (derived from subdistricts, wards or communes) comprising a group of households in a geographic location (ICF International, 2012). The clusters are analogous to communities in this paper, as in previous studies (Gupta and Mahy, 2003; Stephenson, et al, 2007; Magadi 2011). The multilevel modelling places particular emphasis on contextual national and community level factors, with particular reference to contextual HIV/AIDS factors, and the extent of variation in teenage childbearing across countries. The three-level random intercepts Logistic regression model applied may be expressed as:

Logit $\pi_{i j k}=X^{\prime}{ }_{i j k} \beta+u_{j k}+v_{k}$ where: $\pi_{\mathrm{ijk}}$ is the probability of teenage childbearing for an individual $i$, in the $j^{\text {th }}$ cluster in the $k^{\text {th }}$ country; $X^{\prime}{ }_{i j k}$ is the vector of covariates defined at the individual/household, cluster or country level; $\beta$ is the associated vector of usual regression parameter estimates; and the quantities $v_{k}$, and $u_{j k}$ are the residuals at the country and cluster level, respectively. These are assumed to have normal distribution with mean zero and variances $\sigma_{v}^{2}$ and $\sigma_{u}^{2}$ (Goldstein, 2003).

The estimates of country and cluster - level variances were used to calculate intracommunity and intra-country correlation coefficients to examine the extent to which the risk of teenage childbearing is clustered within communities or countries in SSA. These were derived before and after taking into account the effect of significant covariates. We note that since communities are nested within countries (i.e. individuals in the same community are also in the same country), the intra-community correlations include country variances 
(see, for example, Siddiqui et al, 1996). Thus, the intra-country $\left(\rho_{v}\right)$ and intra-community $\left(\rho_{u}\right)$ correlation coefficients are derived, respectively, as follows:

$$
\rho_{v}=\frac{\sigma_{v}^{2}}{\sigma_{v}^{2}+\sigma_{u}^{2}+\sigma_{e}^{2}} \quad \text { and } \quad \rho_{u}=\frac{\sigma_{v}^{2}+\sigma_{u}^{2}}{\sigma_{v}^{2}+\sigma_{u}^{2}+\sigma_{e}^{2}}
$$

where: $\quad \sigma_{\mathrm{v}}{ }^{2}$ is the country-level variance; $\sigma_{\mathrm{u}}{ }^{2}$ is community/cluster-level variance; and $\sigma_{e}{ }^{2}$ is individual-level variance. The level- 1 residuals, $e_{i j k}$, for multilevel logistic regression model, are assumed to have a standard logistic distribution with mean zero and variance $\pi^{2} / 3$, where $\pi$ is the constant 3.1416 (See, for example, Hedeker and Gibbsons, 1996).

To enable multiple comparison of country effects, 95 percent simultaneous confidence intervals (Goldstein and Healy, 1995) of country-level residuals were constructed to examine country variations in teenage childbearing. These were derived before and after controlling for contextual country level factors. Countries whose confidence intervals do not overlap are considered to have different levels of teenage childbearing (at $5 \%$ level of significance).

The modelling strategy involves introducing sets of covariates in successive stages, and noting any changes in parameter estimates after adding each variable to establish mechanisms through which contextual factors are linked to teenage childbearing. All interval-level covariates, including contextual national/community variables, age of respondent and time of survey are centred around grand mean values to enable meaningful interpretation of regression intercepts. Interactions between contextual Socio-economic and HIV/AIDS-related variables were considered in the modelling to examine perceived variations in socio-economic determinants of teenage childbearing by HIV/AIDS context. The 
multilevel analysis was undertaken using MLwiN software and second order PQL procedure used for estimation of parameters (Rasbash et al, 2016).

\section{Results}

\section{Descriptive analysis}

The levels of teenage childbearing, along with early sex and teenage marriage, across countries in SSA are presented in Table 2.

(TABLE 2 ABOUT HERE)

The proportion of teenagers aged 15-19 years who already had a birth, or were pregnant at the time of the survey ranges from less than ten percent in Rwanda and Burundi to more than 35 percent in Mozambique, Mali, Liberia, Congo-Brazzaville, Niger and Gabon. The high rates of teenage childbearing in some of the countries may be attributable to high rates of early sexual debut and/or early marriage. For instance, Liberia, Congo-Brazzaville and Gabon have among the highest rates of early sex, while Niger, Mali and Mozambique have the highest rates of teenage marriage. Conversely, the low rates of teenage childbearing in countries such as Burundi and Rwanda is largely associated with relatively late adolescent transitions to adulthood, with low rates of early sex and teenage marriage. It is important to recognize that teenage childbearing may be influenced by a number of factors including other potential contextual determinants such as HIV/AIDS-related and, socio-economic factors. These determinants of teenage childbearing may operate directly or indirectly through early onset of sexual activity and/or marriage. A correlation matrix of potential national factors considered in the analysis (Annex ii) with adolescent demographic transitions is presented in Annex (iii). 


\section{Multivariate results from multilevel Logistic regression models}

\section{Contextual and individual-level determinants of teenage childbearing in SSA.}

The average odds ratios of contextual (country and community) determinants of teenage childbearing, based on a three-level Logistic regression model, are presented in Table 3. The modelling started with the base model, adjusting for age in single years and year of survey before introducing higher level determinants at country level (Model 1) and subsequently introducing lower level determinants at community/cluster (Model 2) and finally controlling for individual/household level variables (Model 3). The unadjusted parameter estimates for each of the national and community factors, added to the base model, are presented in Annex (iv) for reference.

\section{(TABLE 3 ABOUT HERE)}

National factors significantly associated with teenage childbearing in SSA include HIV testing coverage, and HIV prevalence by GDP per capita interaction. Teenagers in countries with higher HIV testing coverage are less likely to experience childbearing, consistent with patterns in the bivariate analysis. The association between teenage childbearing and national HIV testing coverage only becomes significant when community level factors are controlled for. Although higher levels of socio-economic development may be expected to be inversely associated with teenage childbearing, female education is not significant and there is evidence of higher odds of teenage childbearing in countries with higher GDP per capita. Also, there is a significant negative interaction between national HIV prevalence and GDP per capita, suggesting that the positive association between GDP per capita and teenage childbearing is stronger in countries with lower HIV prevalence (Figure 1). The patterns in Figure 1 further suggest that in countries with low GDP per capita, higher HIV 
prevalence is associated with higher teenage childbearing, while the opposite is the case in higher GDP per-capita countries.

\section{(FIGURE 1 ABOUT HERE)}

At community (i.e cluster) level, HIV prevalence and testing coverage are both associated with increased teenage childbearing, even though the unadjusted patterns suggest a negative association (see Annex iv). The positive associations only become apparent when other community covariates are controlled for. These associations persist even when individual/household level covariates are controlled for, suggesting that they are not explained by these factors. While HIV testing coverage at national level was associated with lower teenage childbearing, the pattern is reversed for HIV testing coverage at community level. The association with other community level factors are as expected: higher stigma is associated with increased, while higher socio-economic status (based on average community wealth and female education) is associated with reduced teenage childbearing. For instance, an increase of one year in average years of female education in a community is associated with a 17 percent reduction [i.e average $\mathrm{OR}=0.83$ ] in the odds of teenage childbearing. The association with community wealth and female education are largely explained by individual-level characteristics (analysis not shown), mainly household wealth (for community wealth) and teenage marriage (for female education). These patterns are plausible, especially since lower female educational attainment in communities is likely to be associated with early marriage, leading to higher teenage childbearing.

The patterns for individual/household socio-economic determinants of teenage childbearing controlled for in the model are largely as expected, with secondary education and higher household wealth being associated with reduced odds of teenage childbearing. Urban/rural residence was not significant and therefore excluded from the final model. As would be 
expected, teenage childbearing increases considerably with age. An increase in age by one year between ages 15 and 19 more than doubles the odds of teenage childbearing (Average OR>2.2). Even after controlling for expected higher marriage rates among older adolescents, increasing age is still associated with a substantial increase in the odds of teenage childbearing (OR=1.65 - not shown). Year of survey was not significant in any of the models, providing no evidence of significant trends in teenage childbearing in SSA during the period 2006-2014.

\section{National and community variations in teenage childbearing in sub-Saharan Africa.}

Estimates of country and community variances, controlling only for the effect of age and time of survey (see Annex iv) show significant clustering of teenage childbearing within countries and communities (i.e. clusters) in SSA. The intra-country and intra-cluster correlations suggest that 11 percent of the total variation in teenage childbearing in SSA is attributable to country-level factors while 27 percent of the total variation is attributable to cluster/community factors. After controlling for community and individual/household level factors, about 7 percent of the total unexplained variation in teenage childbearing is attributable to unobserved country level factors, while 15 percent is attributable to unobserved community level factors. The reduction in country effect is solely attributable to contextual country-level factors included in the analysis, while reduction in community effect is largely attributable to cluster-level socio-economic and HIV/AIDS context included in the analysis.

Simultaneous confidence intervals of country residuals before and after contextual countrylevel factors were controlled for are presented in Figure 2a (corresponds to base model in Annex iv) and Figure 2b (Model 1 in Table 3), respectively, for multiple country comparisons. 17 | 
The patterns in Figure 2a suggest that levels of teenage childbearing are lowest in Rwanda and highest in Mozambique. All countries included in the analysis have significantly higher levels of teenage childbearing than Rwanda. On the other hand, Mozambique has significantly higher teenage childbearing than all countries, apart from six Western/Central African countries: Liberia, Congo-Brazzaville, Mali, Niger, Gabon and Guinea.

(FIGURES 2a \& 2b ABOUT HERE)

Simultaneous confidence intervals for country-level residuals, after controlling for contextual country level factors are presented in Figure 2b. The countries are ordered according to teenage childbearing levels in the base model to ease comparison with Figure 2a. Controlling for country-level factors has a notable influence on country effects. For instance, although Burundi has well below average levels of teenage childbearing in the base model, the level is about average once contextual country level factors are controlled for. Indeed, the level for Burundi is not significantly different from countries with highest teenage childbearing levels such as Mozambique and Mali. Although Rwanda is still associated with the lowest level of teenage childbearing, the level is not significantly different from a number of countries (including Gabon which is at the other extreme), once country-level factors are controlled for. Despite having about the same level of teenage childbearing as Kenya and Tanzania in the base model, Senegal has significantly lower teenage childbearing than these two countries once contextual socio-economic and HIV/AIDS country-level factors are controlled for.

\section{Discussion and conclusions}

This study set out to: (i) examine contextual community and national determinants of teenage childbearing in SSA, with particular reference to socio-economic and HIV/AIDSrelated factors; and (ii) explore national variations in teenage childbearing across countries 18 | 
of SSA. The study provides evidence of the importance of contextual community and national determinants, including HIV/AIDS context, independent of individual/household level factors. The patterns on individual/household-level determinants of teenage childbearing controlled for in the analysis are largely consistent with existing literature (Cherry et al 2009; Christofides et al, 2015; Okigbo and Speizer, 2015; Prathan et al, 2015). Patterns observed here provide credence to our findings. With respect to national variations, the results suggest significant variations in teenage childbearing across countries in the SSA region. The country variations are to a large extent explained by contextual socioeconomic and HIV/AIDS country-level factors included in the analysis.

\section{Contextual socio-economic determinants}

The findings on contextual socio-economic determinants of teenage childbearing are more complex and less consistent with patterns observed in previous studies. A number of studies on neighbourhood socio-economic status and teenage childbearing (mainly in industrialised societies) tend to suggest an increased risk among teenagers in deprived neighbourhoods (McCulloch, 2001; South and Baumer, 2001; Cherry et al 2009; Penman-Aguilar et al., 2013). While observed patterns at community level (i.e an inverse association between teenage childbearing and community wealth or female education) are consistent with previous research (Gupta and Mahy, 2003), there is no evidence of similar associations with national wealth or female education. Although a recent analysis of World Bank data for 51 African countries identified both female literacy and GDP per-capita to have significant inverse bivariate correlations with teenage pregnancy (Odejimi and Bellingham-Young, 2014), this study provides no evidence that national female education is significant while GDP per capita shows an opposite pattern. 
A number of factors may explain the apparent positive association between national GDP per capita and teenage childbearing observed here. Higher teenage childbearing in poor communities in the United States had been attributed to pregnant adolescents in deprived neighbourhoods being less likely to voluntarily terminate a pregnancy than their counterparts in wealthier communities (South and Baumer, 2001). It is possible that restrictive abortion laws and pronounced income inequalities in most countries of SSA may imply that higher GDP does not necessarily translate into better access of reproductive health services for pregnancy termination or contraception. For instance, although Gabon has substantially higher GDP per capital than the other SSA countries included in the analysis (World Bank, 2017), a significant proportion of the country's population still lives in poverty due to extreme inequality. The IMF (2015) notes that 'Despite oil wealth, economic growth for most of the past 15 years has been lacklustre and has not been inclusive.... weak institutions and governance, a shallow financial sector, and a poor business environment have been obstacles to transforming the oil wealth into better living conditions for the population' (P.4). Furthermore, higher GDP per capita in SSA countries may be associated with greater mobility due to better transport infrastructure and greater social networking opportunities that may increase the prevalence of teenage sexual activity (Magadi, 2013) and childbearing. The patterns observed here support the argument of higher income and development at national level resulting in increased opportunities for transactional or extramarital sex (Rodrigo and Rajapakse, 2010) which in the absence of contraception is likely to lead to increased teenage childbearing.

Besides wealth, female education or literacy had also previously been observed to have a significant inverse bivariate relationship with teenage pregnancy in Africa (Odejimi 
and Bellingham-Young, 2014). In this study, although the bivariate and unadjusted associations between national average years of female education and teenage childbearing showed an inverse relationship (albeit weak and not significant - see Annexes iii \& iv), the direction of the relationship is reversed (but remains non-significant) when other national factors are taken into consideration (Table 3). It is possible that in the bivariate association, the association between teenage childbearing and female education is confounded with the effect of other factors (e.g. HIV testing coverage) which have significant correlations with average female education (see Annex (iii)). However, the lack of evidence of an inverse association between national female education and teenage childbearing is surprising, especially since higher education is expected to facilitate contraceptive use which is an effective way of preventing pregnancy among sexually active teenagers (Chandra-Mouli et al., 2014). It is possible that in many SSA settings, higher overall contraceptive prevalence may not necessarily translate into higher contraceptive use by teenagers if such services are not youth friendly and not designed to specifically cater for reproductive health needs of adolescents. It has been noted that adolescents (especially those who are unmarried) in low and middle income countries face a number of barriers in obtaining and correctly/consistently using contraception (Chandra-Mouli et al., 2014). Despite a widespread desire to limit or delay childbearing, more than 40 percent of unmarried adolescents in most SSA countries have an unmet need for contraception (Hindin and Fatusi, 2009).

\section{HIV/AIDS context}

Of particular interest in this study is the effect of HIV context on teenage childbearing. At the national level, HIV testing coverage has an inverse association with teenage childbearing, and a significant negative interaction between HIV prevalence and GDP per 
capita suggests that a positive association between national GDP per capita and teenage childbearing is stronger in countries with lower HIV prevalence. The inverse association between teenage childbearing and HIV testing coverage at national level seems consistent with the inverse correlation between healthcare expenditure and teenage pregnancy observed in a previous study involving analysis of World bank data (Odejimi and BellinghamYoung, 2014).

The significant interaction between HIV prevalence and GDP per capita is not surprising, given the expected complex association between the two (Fotson, 2008). Given the perceived mechanisms through which higher national income/development may lead to increased teenage childbearing - i.e. increased transactional or extramarital sex (Rodrigo and Rajapakse, 2010), it is possible that higher HIV prevalence may: (i) act as a deterrent to transactional or extramarital sex; or/and (ii) lead to higher use of condoms which would offer protection for both HIV infection and pregnancy. The fact that the interaction further suggests that higher HIV prevalence is associated higher teenage childbearing in countries with low GDP per-capita, while the opposite is the case in countries with higher GDP percapita suggests that countries with higher national resources are better equipped to counteract the adverse impact of HIV on teenage childbearing.

At community level, HIV prevalence, testing coverage and HIV/AIDS stigma all have positive associations with teenage childbearing, while HIV/AIDS awareness has an inverse relationship. The positive association between HIV prevalence at community level and teenage childbearing may be attributable to the two sharing a common risk factor unprotected sex. One may expect interventions or policies/programmes aimed at reducing unprotected sex to be effective at fighting both HIV and pregnancy. However, this relationship is quite complex, as pointed out by Dulfo et al (2014). The patterns observed 
here may suggest that, either (i) widespread unprotected sex is a mutual risk factor for both HIV and pregnancy, and/or (ii) HIV behavioural response in high prevalence settings focusing more on reduction of casual or premarital sex (rather than abstinence or condom use) which would not be effective in preventing pregnancy. Although condom use for HIV prevention in most SSA settings is highly stigmatised (Marston and King 2006; Cordero, 2014), efforts promoting condom use with emphasis on pregnancy prevention are more widely acceptable (Cleland and Ali 2006; Cordero, 2014). As noted earlier, it is also possible that HIV prevention curricula that focus on an abstinence-until-marriage message may encourage early marriage and unlikely to reduce teenage pregnancy (Duflo et al., 2014). However, the fact that the observed positive association between community HIV prevalence and teenage childbearing is partly explained by early sex rather than teenage marriage (analysis not shown) supports the former explanation rather than the latter. The mechanisms though which HIV/AIDS stigma and awareness are associated with teenage childbearing are likely to be complex. It is possible that reduced condom use associated with HIV/AIDS stigma may lead to increased teenage childbearing. The observed positive association between both HIV prevalence and testing coverage at community level and teenage childbearing only become apparent when other community level factors (including female education, average wealth, HIV/AIDS awareness and stigma) are controlled for in the model. As noted by Coates et al (2008), effectiveness of behavioural strategies in HIV affected populations could be enhanced by aiming for many goals (e.g. delayed onset of sexual activity, condom use, etc), achieved by multilevel approaches at family, community and population levels. This has been echoed by Mmeje et al (2014) who noted that regions of high HIV prevalence in SSA require multipurpose prevention technologies to enhance options beyond contraception and prevention of HIV. 


\section{Study limitations}

It is important to recognize some key data limitations that should be born in mind when interpreting our findings. First, we note that the cross-sectional nature of the DHS limits our ability to make causal inferences. As noted in the introduction, the socio-economic status of teenagers and their households may have been influenced by early childbearing (e.g. teenagers are likely to drop out of school when they become pregnant), leading to reverse causality. However, this study focuses on contextual (community and national) rather than individual/household-level socio-economic predictors of teenage childbearing which are less susceptible to the problem of reverse causality. Furthermore, the individual-level educational attainment controlled for in the final model uses secondary+ education as the highest level before which school drop-out would be considered to occur too early to be influenced by childbearing (Gupta and Mahy,2003). Nevertheless, it is possible that some of the contextual factors of interest (especially community-level factors) may have changed if the teenagers moved residence or other circumstances changed since childbirth. In particular, the rapidly changing HIV treatment scenario may have altered the HIV context. Restricting the analysis to teenagers aged 15-19 implies that most childbearing experiences would have occurred in the recent period, minimizing potential changes in contextual factors. Nonetheless, we recognize that the patterns observed here reflect association patterns rather than infer causality.

Second, sample size limitations both with respect to the number of level-3 units (countries) and the number of observations in each level-2 unit (cluster) warrant attention. The number of countries included in the analysis $(n=29)$ is limited in providing adequate statistical power to detect significance of contextual country level factors. A detailed discussion of the issue 
of sample size requirements in multilevel analysis is available elsewhere (Magadi, 2011), but we recognize that statistical power for higher level estimates depends on the number of groups (Snijders, 2005). It is, therefore, possible that the lack of significance of some of the key contextual factors of interest, such as national female education, HIV/AIDS awareness and stigma, may be partly due to limited statistical power to detect significant associations at country-level.

The number of women per cluster, used to derive cluster-level aggregate measures (approximate mean of 26; median of 25) provides a proxy for theoretical average for all women in the cluster. Although the sample mean may, in principle, differ markedly from the overall mean, simulations based on average education within a cluster of approximately 25 respondents per cluster suggest that such bias is likely to be small when education effects on timing of first birth are estimated from the Demographic and Health Surveys (DHS) in SSA when intra-cluster correlation (ICC) is over $20 \%$ (Kravdal, 2006). Although biases are likely to be small given ICC of $27 \%$ for the analysis presented here, it is possible that potentially large standard errors for community averages derived from binary rather than continuous variables (e.g. HIV prevalence and testing coverage) may have limited the statistical power to detect significance of these community-level factors.

Finally, we recognize that the survey years (2006-2014) cover a span of almost a decade during which HIV/AIDS evolved from a deadly disease to a manageable chronic condition (while undoubtedly remaining a major public health concern). Furthermore, some of the data relate to a period as far back as a decade ago and may not be representative of the current state of teenage pregnancy in SSA. However, it is unlikely that the patterns observed 
here have been significantly affected by the time span since year of survey (or potential interactions with key variables) were not significant in any of the models.

(WORD COUNT=6735) 


\section{References}

Allen T, Heald S. (2004). HIV/AIDS policy in Africa: what has worked in Uganda and what has failed in Botswana? Journal of International development 16(8):1141-1154.

Auerbach JD, Hayes RJ, \& Kandathila SM. (2006). Overview of effective and promising interventions to prevent HIV infection. In Ross, et al., (Eds). Preventing HIV/AIDS in Young People: A Systematic Review of the Evidence from Developing Countries. WHO Technical Report Series 938:43-78.

Barnett, T. and Parkhurst. J. (2005). HIV/AIDS: Sex, abstinence, and behaviour change. The Lancet Infectious Diseases 5(9): 590-3

Bissell, M. (2000). Socio-economic outcomes of teen pregnancy and parenthood: A review of the literature. Canadian Journal of Human Sexuality 9 (3): 191-204.

Brahmbhatt, H., Kågesten, A., Emerson, M., Decker, M.R., Olumide, A.O., Ojengbede, O., Lou, C., Sonenstein, F.L., Blum, R.W., Delany-Moretlwe, S. (2014). Prevalence and determinants of adolescent pregnancy in urban disadvantaged settings across five cities. Journal of Adolescent Health 55(6):S48-S57

Brewster, K.L. (1994). Neighborhood context and the transition to sexual activity among young black women. Demography 31(4): 603-614.

Brewster, K.L., Billy, J.O.G., Grady, W.R. (1993). Social Context and Adolescent Behavior: The Impact of Community on the Transition to Sexual Activity. Social Forces 71(3):713-740. 
Chandra-Mouli, V., DR McCarraher, SJ Phillips, NE Williamson and G. Hainsworth. (2014). Contraception for adolescents in low and middle income countries: needs, barriers, and access. Reproductive Health. 11(1). DOI: 10.1186/1742-4755-11-1

Chen, X.-K., Wen, S.W., Fleming, N., Demissie, K., Rhoads, G.G., Walker, M. (2007). Teenage pregnancy and adverse birth outcomes: A large population based retrospective cohort study. International Journal of Epidemiology 36(2):368-373.

Cherry, A.L., Byers, L., Dillon, M. (2009). A global perspective on teen pregnancy (Chapter 21). Maternal and Child Health: Global Challenges, Programs, and Policies, pp. 375-397.

Christofides, N.J., Jewkes, R.K., Dunkle, K.L., McCarty, F., Shai, N.J., Nduna, M., Sterk, C. (2015). Risk factors for unplanned and unwanted teenage pregnancies occurring over two years of follow-up among a cohort of young South African women. Global Health Action, 8 (1), art. no. 23719.

Christofides, N.J., Jewkes, R.K., Dunkle, K.L., Nduna, M., Shai, N.J., Sterk, C. (2014). Early adolescent pregnancy increases risk of incident HIV infection in the eastern cape, south africa: A longitudinal study. Journal of the International AIDS Society, 17, art. no. 18585.

Clark, S. (2004). Early marriage and HIV risks in sub-Saharan Africa. Studies in Family Planning 35 (3):149-160.

Cleland, J and Ali, M. (2006). Sexual abstinence, contraception, and condom use by young African women: a secondary analysis of survey data. The Lancet. 368(9549):1788 - 1793 
Coates, T.J., Richter, L and Caceres, C. (2008). Behavioural strategies to reduce HIV transmission: how to make them work better. The Lancet 372(9639):669-684

Cordero CJ. (2014). HIV prevention and marriage: peer group effects on condom use acceptability in rural Kenya. Soc Sci Med.116:169-77.

Denno et al. (2015). Effective Strategies to Provide Adolescent Sexual and Reproductive Health Services and to Increase Demand and Community Support. Journal of Adolescent Health 56(1):s22-s41.

Diamond, I., Clements, S., Stone, N., Ingham, R. (1999). Spatial variation in teenage conceptions in south and west England. Journal of the Royal Statistical Society. Series A: Statistics in Society 162(3):273-289.

Duflo, E., Dupas, P., Kremer, M. (2014). Education, HIV, and Early Fertility: Experimental Evidence from Kenya. NBER Working Paper No. 20784, JEL No. 112,125,138,012 . National Bureau of Economic Research. http://www.nber.org/papers/w20784.pdf (Accessed 04 March 2016).

Fortson, Jane. (2008). The Gradient in Sub-Saharan Africa: Socioeconomic Status and HIV/AIDS. Demography 45(2): 303-322.

Ganchimeg, T., Ota, E., Morisaki, N., Laopaiboon, M., Lumbiganon, P., Zhang, J., Yamdamsuren, B., Temmerman, M., Say, L., Tunçalp, O., Vogel, J.P., Souza, J.P., Mori, R. (2014). Pregnancy and childbirth outcomes among adolescent mothers: a World Health 291 
Organization multicountry study. BJOG : An International Journal of Obstetrics and Gynaecology 121(Suppl 1):40-48.

Goldstein, H. (2003). Multilevel statistical models (3rd edition). London: Arnold.

Goldstein, H. \& Healy M.R.J. (1995). The graphical representation of a collection of means Journal of the Royal Statistical Society, Series A, 158:175-7.

Gupta GR, Parkhurst JO, Ogden JA, Aggleton P, Mahal A. (2008). Structural approaches to HIV prevention. The Lancet 372(9640):764-75.

Gupta, N and Mahy, M. (2003). Adolescent childbearing in sub-Saharan Africa: Can increased schooling alone raise ages at first birth? Demographic Research 8(4):93-106.

Hedeker, D and R.D. Gibbsons. (1996). MIXOR: a computer programme for mixed effects ordinal regression analysis|l. Computer Methods and Programs in Biometrics 49:157-176.

Hindin and Fatusi. (2009). Adolescent Sexual and Reproductive Health in Developing Countries: An Overview of Trends and Interventions. International Perspectives on Sexual and Reproductive Health. 35(2):58-62.

ICF International. (2012. Demographic and Health Survey Sampling and Household Listing Manual. MEASURE DHS, Calverton, Maryland, U.S.A.: ICF International 
ICF Macro. (2010). HIV Prevalence Estimates from the Demographic and Health Surveys.

Calverton, Maryland. ICF Macro.

International Monetary Fund. 2015. Gabon: Staff Report for the 2014 Article IV

Consultation. IMF Country Report No. 15/47.

http://www.imf.org/external/pubs/ft/scr/2015/cr1547.pdf (accessed 11 March 2016)

Kothari, MT, S. Wang, SK. Head, and N. Abderrahim. (2012). Trends in Adolescent

Reproductive and Sexual Behaviors. DHS Comparative Reports No. 29. Calverton, Maryland, USA: ICF International.

Kravdal, O. (2006). A simulation-based assessment of the bias produced when using averages from small DHS clusters as contextual variables in multilevel models. Demographic Research 15(1):1-20. http://www.demographic-research.org/volumes/vol15/1/15-1.pdf (accessed 12 August 2016).

Magadi, M. (2006). Poor pregnancy outcomes among adolescents in South Nyanza region of Kenya. African Journal of Reproductive Health. 10 (1):26-38.

Magadi, M. A. (2011). Household and community HIV/AIDS status and child malnutrition in sub-Saharan Africa. Social Science \& Medicine 73: 436-446. 
Magadi M.A. (2013). Migration as a Risk Factor for HIV Infection among Youths in SubSaharan Africa: Evidence from the DHS. The ANNALS of the American Academy of Political and Social Science, pp.136-59.

Marston C, King E. (2006). Factors that shape young people's sexual behaviour: a systematic review. The Lancet, 368(9547):1581-6.

McCulloch, A. (2001). Teenage childbearing in Great Britain and the spatial concentration of poverty households. Journal of Epidemiology and Community Health, 55 (1):16-23.

Mmeje, O., Cohen, C.R., Murage, A., Ong'Ech, J., Kiarie, J., Van Der Poel, S. (2014). Promoting reproductive options for HIV-affected couples in sub-Saharan Africa. BJOG: An International Journal of Obstetrics and Gynaecology 121(s5):79-86.

Odejimi, O., Bellingham-Young, D. (2014). A policy pathway to reducing teenage pregnancy in Africa. Journal of Human Growth and Development 24 (2):135-141.

Okigbo, C.C., Speizer, I.S. (2015). Determinants of sexual activity and pregnancy among unmarried young women in urban Kenya: A cross-sectional study. PLoS ONE, 10 (6), art. no. e0129286.

Paranjothy, S., Broughton, H., Adappa, R., Fone, D. (2009). Teenage pregnancy: Who suffers? Archives of Disease in Childhood 94(3):239-245.

Parikh, S.A. (2007). The Political Economy of Marriage and HIV: The ABC Approach, Safe 32 | 
Infidelity, and Managing Moral Risk in Uganda. American Journal of Public Health, 97

(7):1198-1208.

Pebley AR, Goldman N and Rodriguez G. (1996). Prenatal and delivery care and childhood immunization: do family and community matter? Demography, 1996, 33(2):213-247.

Penman-Aguilar, A., Carter, M., Christine Snead, M., Kourtis, A.P. (2013). Socio-economic disadvantage as a social determinant of teen childbearing in the U.S. Public Health Reports 128 (SUPPL. 1): 5-22.

Phillips, S.J., Mbizvo, M.T. (2016). Empowering adolescent girls in Sub-Saharan Africa to prevent unintended pregnancy and HIV: A critical research gap. International Journal of Gynecology and Obstetrics 132(1):1-3.

Pradhan, R., Wynter, K., Fisher, J. (2015). Factors associated with pregnancy among adolescents in low-income and lower middle-income countries: A systematic review. Journal of Epidemiology and Community Health 69 (9):918-924.

Rasbash, J., Steele, F., Browne, W.J. and Goldstein, H. (2015). A User's Guide to MLwiN, v2.33. Centre for Multilevel Modelling, University of Bristol. http://www.bristol.ac.uk/cmm/media/software/mlwin/downloads/manuals/2-33/manualweb.pdf (accessed 10 March 2016).

Rodrigo, C. and Rajapakse, S, (2010). HIV, poverty and women. International Health 2: 9-16 
Sedgh G, Finer LB, Bankole A, Eilers MA, Singh S. (2015). Adolescent pregnancy, birth, and abortion rates across countries: levels and recent trends. J Adolesc Health. 56(2):223-30.

Siddiqui, O., Hedeker, D., Flay, B.R., Hu, F.B. (1996). Intra-class correlation estimates in a school-based smoking prevention study: Outcome and mediating variables, by sex and ethnicity. Am J Epidemiol 144(4):425-33.

Snijders, T. A. B. (2005). Power and sample size in multilevel modelling. In B. S. Everitt, \& D. C. Howell (Eds.). Encyclopaedia of Statistics in Behavioural Science, 3, pp. 1570e1573.

South, S.J., Baumer, E.P. (2001). Community effects on the resolution of adolescent premarital pregnancy. Journal of Family Issues, 22(8):1025-1043.

Tenkorang EY, Maticka-Tyndale E (2014). Individual- and community-level influences on the timing of sexual debut among youth in Nyanza, Kenya. Int Perspect Sex Reprod Health, 40(2):68-78.

Stephenson, R., Baschieri,A., Clements,S., Hennink, M. and Madise, N. (2007). Contextual Influences on Modern Contraceptive Use in Sub-Saharan Africa". American Journal of Public Health. 97(7):1233-1240.

UNAIDS (2010). Combination HIV Prevention: Tailoring and Coordinating Biomedical, Behavioural and Structural Strategies to Reduce New HIV Infections. A UNAIDS Discussion Paper. UNAIDS, Geneva. 
United Nations. (2015). World Population Prospects: The 2015 Revision, Volume II:

Demographic Profiles. Department of Economic and Social Affairs, Population Division (ST/ESA/SER.A/380).

United Nations Fund for Population Activities (UNFPA). (2005). The Unmapped Journey: Adolescents, Poverty and Gender. Chapter 5. State of World Populations 2005. New York: UNFPA.

United Nations Fund for Population Activities (UNFPA) (2014). State of the World Population 2014: The Power of 1.8 Billion: Adolescents, Youth and the Transformation of the Future. UNFPA .https://www.unfpa.org/sites/default/files/pub-pdf/EN-SWOP14-Report_FINALweb.pdf (Accessed 15 August 2016)

Uthman, O.A., Kongnyuy, E.J. (2008). A multilevel analysis of effect of neighbourhood and individual wealth status on sexual behaviour among women: Evidence from Nigeria 2003 Demographic and Health Survey. BMC International Health and Human Rights, 8, art. no. 9, Vu, L., Zieman, B., Banura, C., Okal,J., Elang, M., Ampwera, R., Caswell, G., Amanyire, D., Alesi, J., Yam, E. (2017). Increasing uptake of HIV, sexually transmitted infection, and family planning services, and reducing HIV-related risk behaviors among youth living with HIV in Uganda. Journal of Adolescent Health 60(2): S22-S28 
Vundule, C., Maforah, F., Jewkes, R., Jordaan, E.(2001). Risk factors for teenage pregnancy among sexually active black adolescents in Cape Town. South African Medical Journal, 91 (1), pp. 73-80.

Were M. (2007). Determinants of teenage pregnancies: The case of Busia District in Kenya. Economics and Human Biology 5(2):322-339.

Woog et al. (2015). Adolescent Women's Need for and Use of Sexual and Reproductive Health Services in Developing Countries. Guttmacher Institute: New York.

World Bank (2017). GDP per capita, PPP (current international \$), World Development Indicators database. http://data.worldbank.org/indicator/NY.GDP.PCAP.PP.CD?locations =AO\&order=wbapi_data_value_2014+wbapi_data_value+wbapi_data_value-last\&sort=desc (Accessed 7 April 2017). 
Table 1: A summary of the study sample

\begin{tabular}{|c|c|c|c|c|}
\hline Country & $\begin{array}{l}\text { Year of } \\
\text { survey }\end{array}$ & $\begin{array}{r}\text { Number of } \\
\text { clusters }\end{array}$ & $\begin{array}{r}\text { Women aged } \\
15-49 \text { years }\end{array}$ & $\begin{array}{l}\text { Teenage women } \\
\text { aged } 15-19 \text { years }\end{array}$ \\
\hline Burkina Faso & 2010 & 574 & 17087 & 3349 \\
\hline Burundi & 2010 & 376 & 9389 & 2377 \\
\hline Cameroon & 2011 & 580 & 15426 & 3590 \\
\hline Congo-Brazzaville & 2009 & 241 & 6550 & 1311 \\
\hline DR Congo & 2013-14 & 540 & 18827 & 3981 \\
\hline Cote dlvoire & $2011-12$ & 352 & 10060 & 1997 \\
\hline Ethiopia & 2011 & 650 & 16515 & 3835 \\
\hline Gabon & 2012 & 336 & 8422 & 1834 \\
\hline Gambia & 2013 & 281 & 10233 & 2463 \\
\hline Ghana & 2014 & 427 & 9396 & 1756 \\
\hline Guinea & 2012 & 300 & 9142 & 1994 \\
\hline Kenya & $2008-09$ & 400 & 8444 & 1767 \\
\hline Lesotho & 2009 & 400 & 7624 & 1840 \\
\hline Liberia & 2013 & 322 & 9239 & 1915 \\
\hline Malawi & 2010 & 849 & 23020 & 5040 \\
\hline Mali & $2012-13$ & 585 & 10424 & 1918 \\
\hline Mozambique & 2009 & 270 & 6413 & 1031 \\
\hline Namibia & 2013 & 554 & 10018 & 1857 \\
\hline Niger & 2012 & 480 & 11160 & 1901 \\
\hline Rwanda & 2010 & 492 & 13671 & 2963 \\
\hline Sao Tome & 2008-09 & 104 & 2615 & 540 \\
\hline Senegal & 2010-11 & 392 & 15688 & 3604 \\
\hline Siera Leone & 2013 & 435 & 16658 & 4051 \\
\hline Swaziland & $2006-07$ & 275 & 4987 & 1265 \\
\hline Tanzania & $2011-12$ & 916 & 10967 & 2477 \\
\hline Togo & 2013-14 & 330 & 9480 & 1733 \\
\hline Uganda & 2011 & 470 & 12153 & 2451 \\
\hline Zambia & 2013-14 & 722 & 16411 & 3686 \\
\hline Zimbabwe & $2010-11$ & 406 & 9171 & 1980 \\
\hline Total & 2006-14 & 13975 & 329190 & 70506 \\
\hline
\end{tabular}


Table 2: Percent of adolescents in sub-Saharan Africa who had early sex, teen marriage and teen childbearing

\begin{tabular}{|c|c|c|c|c|}
\hline \multirow[b]{3}{*}{ Country } & \multicolumn{3}{|c|}{ Percent of 15-19 year old females who had } & \multirow[b]{3}{*}{ Cases } \\
\hline & Early & Teen & $\overline{\text { Teen }}$ & \\
\hline & $\operatorname{Sex}^{1}$ & Marriage $^{2}$ & childbearing $^{3}$ & \\
\hline Burkina Faso & 6.96 & 29.83 & 22.60 & 3349 \\
\hline Burundi & 3.79 & 9.34 & 9.42 & 2377 \\
\hline Cameroon & 16.52 & 26.27 & 26.77 & 3590 \\
\hline Congo-Brazzaville & 24.41 & 23.72 & 35.70 & 1311 \\
\hline DR Congo & 19.92 & 27.15 & 30.24 & 3981 \\
\hline Cote dlvoire & 20.58 & 21.43 & 28.54 & 1997 \\
\hline Ethiopia & 7.90 & 24.72 & 13.27 & 3835 \\
\hline Gabon & 21.97 & 17.18 & 35.50 & 1834 \\
\hline Gambia & 5.97 & 25.54 & 18.92 & 2463 \\
\hline Ghana & 11.45 & 7.57 & 13.21 & 1756 \\
\hline Guinea & 22.37 & 34.45 & 34.10 & 1994 \\
\hline Kenya & 11.60 & 15.45 & 20.32 & 1767 \\
\hline Lesotho & 8.86 & 18.59 & 20.49 & 1840 \\
\hline Liberia & 25.64 & 19.79 & 37.08 & 1915 \\
\hline Malawi & 12.02 & 26.15 & 26.13 & 5040 \\
\hline Mali & 19.55 & 43.48 & 38.16 & 1918 \\
\hline Mozambique & 20.56 & 42.68 & 43.16 & 1031 \\
\hline Namibia & 7.81 & 6.62 & 20.36 & 1857 \\
\hline Niger & 18.46 & 54.87 & 35.61 & 1901 \\
\hline Rwanda & 4.69 & 3.37 & 5.84 & 2963 \\
\hline Sao Tome & 11.11 & 25.74 & 26.30 & 540 \\
\hline Senegal & 11.46 & 28.63 & 21.42 & 3604 \\
\hline Siera Leone & 18.17 & 18.79 & 27.18 & 4051 \\
\hline Swaziland & 7.59 & 7.67 & 22.92 & 1265 \\
\hline Tanzania & 8.68 & 21.11 & 22.37 & 2477 \\
\hline Togo & 10.39 & 14.43 & 17.20 & 1733 \\
\hline Uganda & 11.63 & 23.34 & 26.93 & 2451 \\
\hline Zambia & 12.67 & 17.04 & 28.95 & 3686 \\
\hline Zimbabwe & 3.99 & 23.23 & 22.58 & 1980 \\
\hline Total & 12.99 & 22.71 & 24.42 & 70506 \\
\hline
\end{tabular}


Table 3: Multilevel Logistic regression average odds ratios (95\% confidence intervals given in brackets) of determinants of teenage childbearing across countries of SSA

\begin{tabular}{|c|c|c|c|c|c|c|}
\hline Parameter & Model 1 & & Model 2 & & Model $3^{f}$ & \\
\hline Age in years & $2.21[2.17,2.25]$ & $*$ & $2.28[2.24,2.32]$ & $*$ & $2.45[2.36,2.55]$ & * \\
\hline Year of survey & $1.04[0.91,1.19]$ & & $1.04[0.91,1.19]$ & & $1.08[0.94,1.24]$ & \\
\hline \multicolumn{7}{|l|}{ Country-level factors } \\
\hline HIV prevalence & $1.85[1.06,3.23]$ & $*$ & $1.73[0.97,3.07]$ & & $1.73[0.96,3.12]$ & \\
\hline HIV testing coverage & $0.87[0.71,1.06]$ & & $0.79[0.64,0.97]$ & $*$ & $0.77[0.62,0.95]$ & $*$ \\
\hline HIV/AIDS stigma & $1.04[0.63,1.71]$ & & $0.86[0.52,1.44]$ & & $0.94[0.56,1.59]$ & \\
\hline HIV awareness & $0.91[0.50,1.64]$ & & $0.91[0.49 .1 .67]$ & & $0.98[0.52,1.83]$ & \\
\hline Female education & $0.89[0.77,1.04]$ & & $1.04[0.89,1.21]$ & & $1.01[0.86,1.18]$ & \\
\hline GDP in $\${ }^{\prime} 000^{\prime}$ & $1.07[1.01,1.15]$ & $*$ & $1.07[1.00,1.14]$ & $*$ & $1.09[1.01,1.17]$ & * \\
\hline HIV prev*GDP interaction & $0.90[0.81,0.99]$ & $*$ & $0.90[0.81,0.99]$ & $*$ & $0.90[0.81,0.99]$ & $*$ \\
\hline \multicolumn{7}{|l|}{ Cluster-level factors } \\
\hline HIV prevalence $\$$ & & & $1.11[1.08,1.14]$ & $*$ & $1.12[1.08,1.15]$ & * \\
\hline HIV testing coverage & & & $1.10[1.09,1.12]$ & $*$ & $1.12[1.10,1.13]$ & * \\
\hline HIV/AIDS stigma & & & $1.13[1.09,1.17]$ & $*$ & $1.12[1.08,1.16]$ & $*$ \\
\hline HIV awareness & & & $0.97[0.95,1.00]$ & & $0.98[0.95,1.01]$ & \\
\hline Female education & & & $0.83[0.82,0.85]$ & $*$ & $0.94[0.92,0.96]$ & $*$ \\
\hline Average wealth & & & $0.81[0.78,0.84]$ & $*$ & $0.96[0.92,1.00]$ & \\
\hline \multicolumn{7}{|l|}{ Random Variance } \\
\hline Country & $0.26(0.070)$ & $*$ & $0.28(0.074)$ & $*$ & $0.29(0.078)$ & $*$ \\
\hline Cluster & $0.62(0.024)$ & $*$ & $0.31(0.019)$ & $*$ & $0.31(0.020)$ & $*$ \\
\hline
\end{tabular}


Figure 1: Predicted probabilities $\$$ of teenage childbearing across countries of sub-Saharan Africa by national GDP per-capita and HIV prevalence

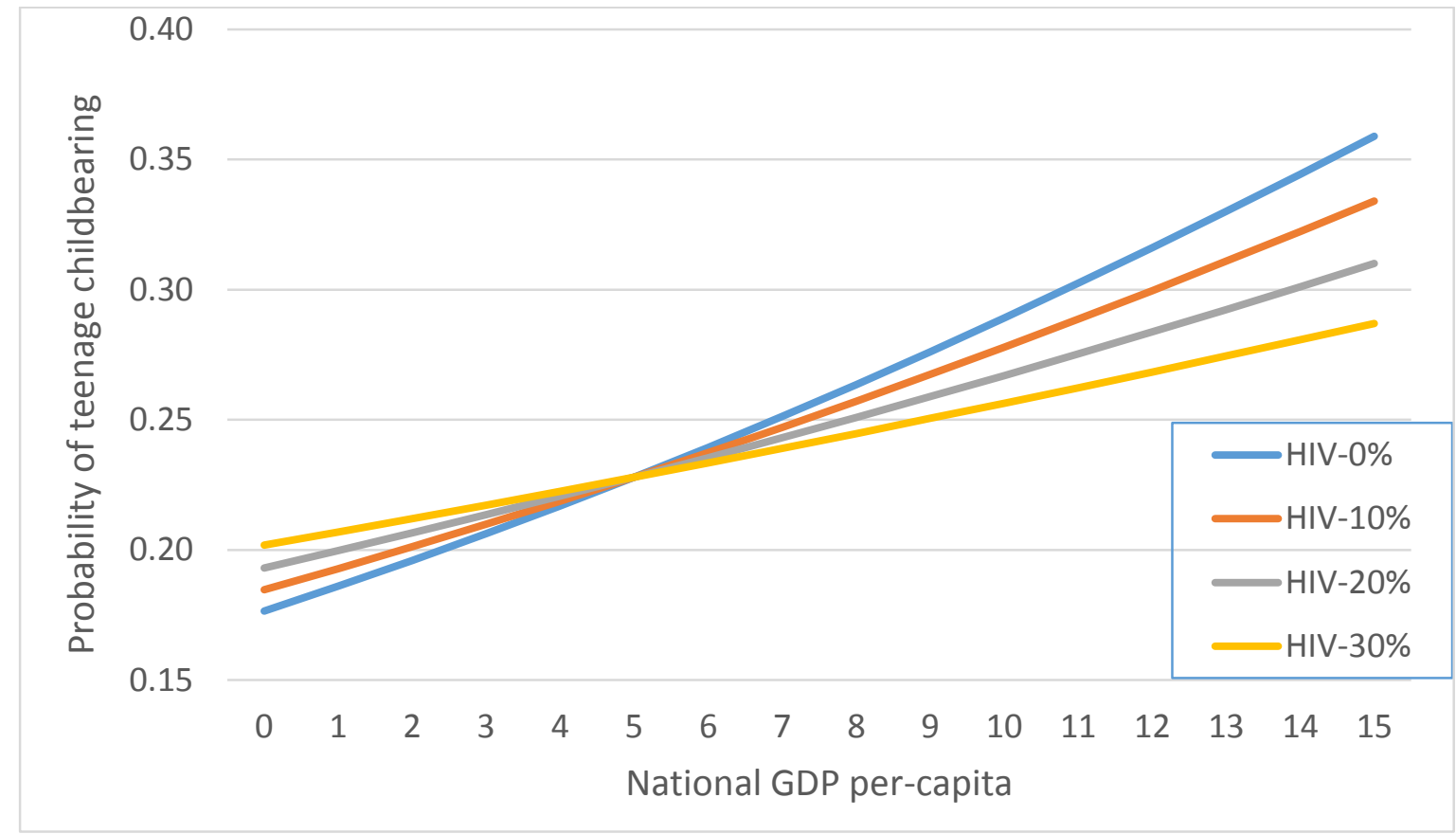

\$Predicted probabilities obtained while holding all other covariates at their mean values 
Figure 2a: Simultaneous confidence intervals (95 percent) for country-level residuals of teenage childbearing (Model 0 )

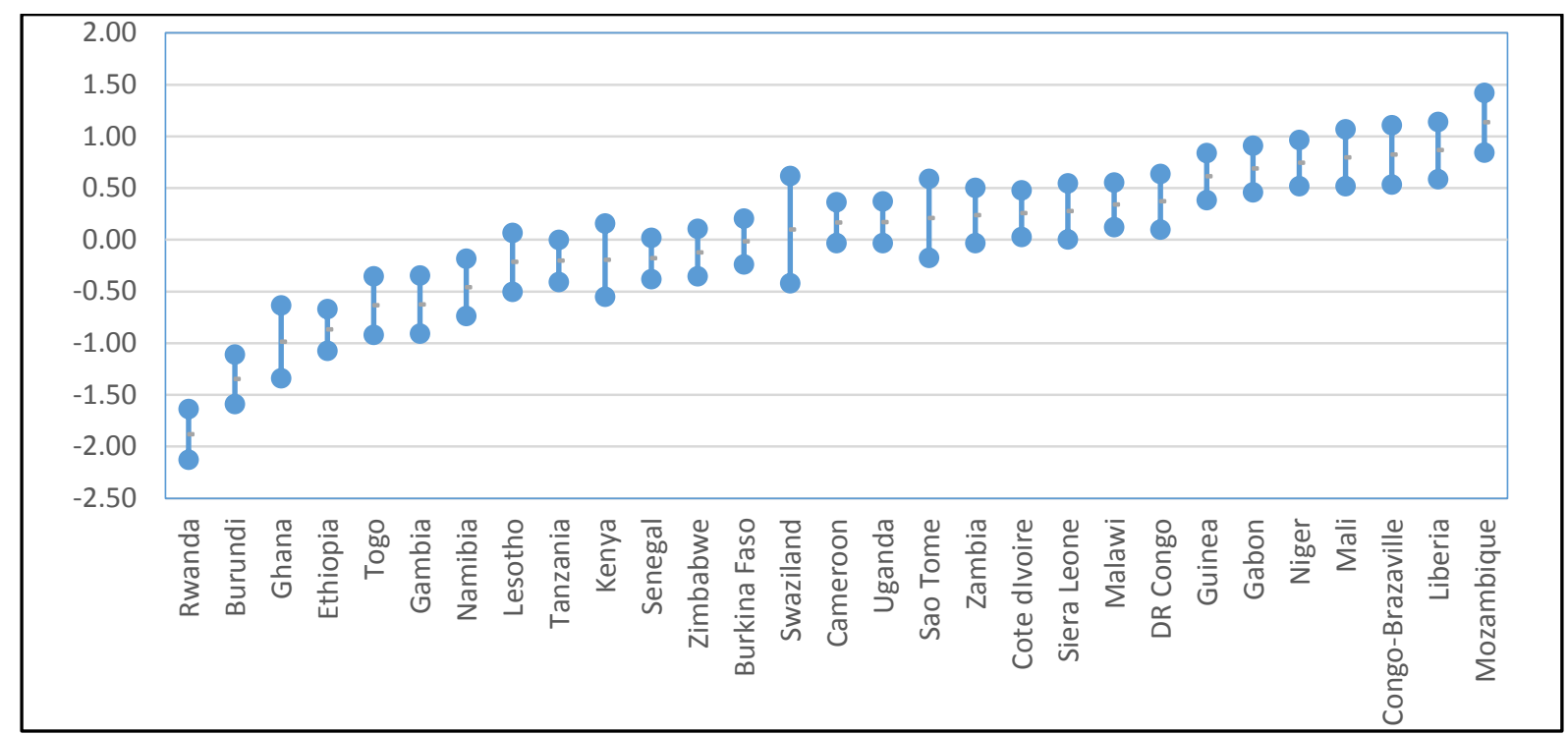

Figure $2 \mathrm{~b}$ : Simultaneous confidence intervals (95 percent) for country-level residuals of teenage childbearing (Model 1 )

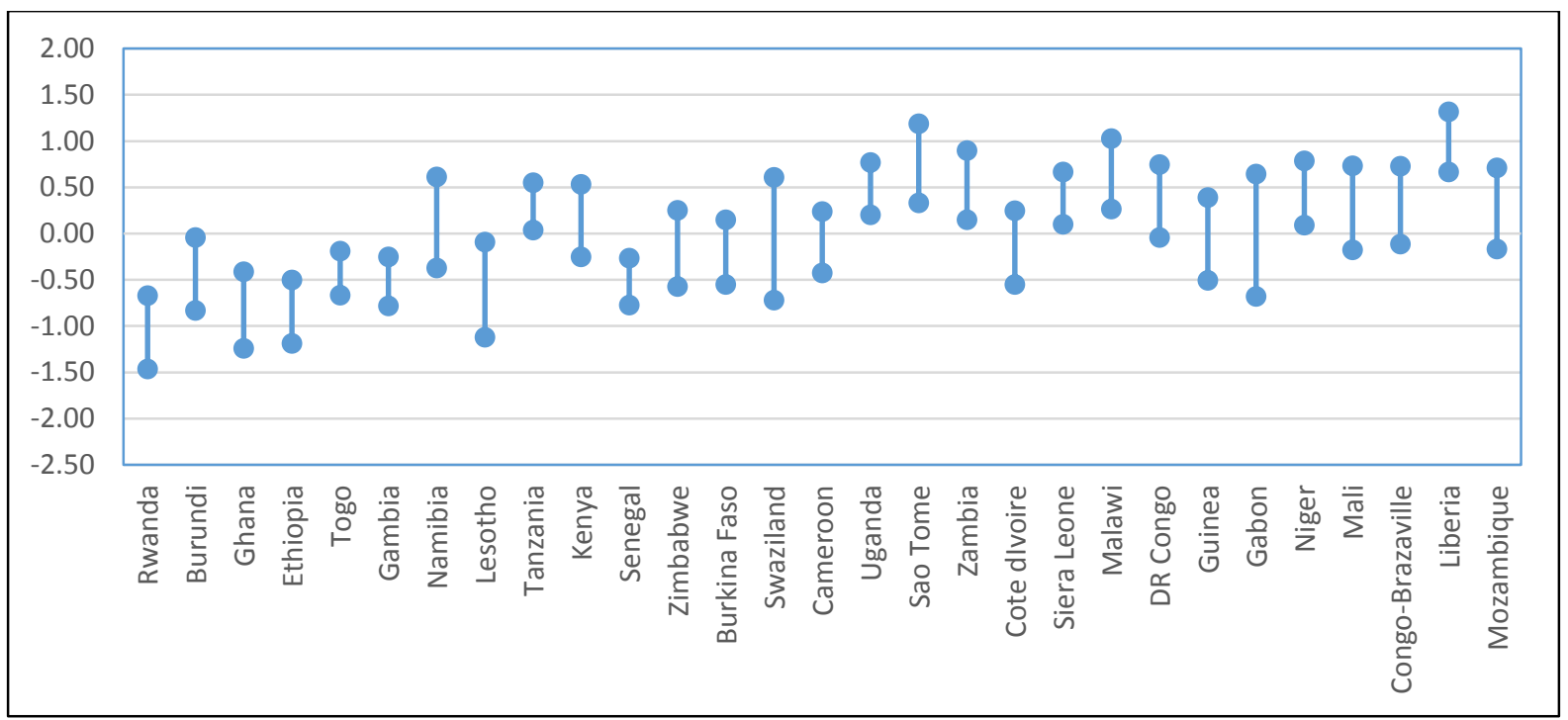


Annex (i) Description of study variables included in the analysis.

\begin{tabular}{|c|c|}
\hline NAME OF VARIABLE & MEASURE \\
\hline \multicolumn{2}{|l|}{ Outcome Variable } \\
\hline Teenage childbearing & $\begin{array}{l}\text { Coded as } 1=\text { if a teenage respondent aged } 15-19 \text { years has ever } \\
\text { had a birth or is pregnant at the time of survey; } 0=\text { otherwise. }\end{array}$ \\
\hline \multicolumn{2}{|c|}{ Contextual Country - level factors } \\
\hline HIV prevalence & $\begin{array}{l}\text { HIV prevalence (\%) among women of reproductive age, ranging } \\
\text { from a low of } 0.4 \text { in Niger to a high of } 31.1 \text { in Swaziland }\end{array}$ \\
\hline HIV testing & $\begin{array}{l}\text { Proportion of women of reproductive age previously tested for } \\
\text { HIV, ranging from } 0.11 \text { in Guinea to } 0.82 \text { in Burundi. }\end{array}$ \\
\hline HIV/AIDS stigma & $\begin{array}{l}\text { Average stigma score }{ }^{1} \text {, ranging from } 0.49 \text { in Namibia to } 3.82 \text { in } \\
\text { Guinea }\end{array}$ \\
\hline HIV/AIDS awareness & $\begin{array}{l}\text { Average awareness score }{ }^{2} \text {, ranges from } 6.12 \text { (DRC) to } 9.46 \\
\text { (Swaziland) }\end{array}$ \\
\hline Female Education & $\begin{array}{l}\text { Average number of years of schooling for women of reproductive } \\
\text { age, ranging from } 1.7 \text { in Niger to } 8.95 \text { in Zimbabwe. }\end{array}$ \\
\hline GDP per capita & $\begin{array}{l}\text { GDP in US\$`000’ estimates from World Bank Indicator database }{ }^{3} \\
\text { for year of survey ranges from } 0.69 \text { (Burundi) to } 17.92 \text { (Gabon). }\end{array}$ \\
\hline \multicolumn{2}{|c|}{ Contextual community - level factors } \\
\hline HIV prevalence & HIV prevalence (\%) among women of reproductive age in cluster \\
\hline HIV testing & $\begin{array}{l}\text { Proportion of women of reproductive age in cluster previously } \\
\text { tested for HIV }\end{array}$ \\
\hline HIV/AIDS stigma & Average stigma score in cluster \\
\hline HIV/AIDS awareness & Average awareness score in cluster \\
\hline Female Education & $\begin{array}{l}\text { Average years of schooling for women of reproductive age in } \\
\text { cluster }\end{array}$ \\
\hline Average wealth & $\begin{array}{l}\text { Average wealth, derived from wealth index of households in } \\
\text { cluster. }\end{array}$ \\
\hline Residence (Ref=Urban) & Place of residence, coded as $1=$ rural residence; $0=$ urban \\
\hline \multicolumn{2}{|c|}{ Period of exposure and trend covariates controlled for } \\
\hline Age of teenager & $\begin{array}{l}\text { Age in single years included to control for duration of exposure to } \\
\text { the risk of pregnancy/childbearing }\end{array}$ \\
\hline Year of survey & Year of survey, ranging from 2006 to 2014 \\
\hline
\end{tabular}

\footnotetext{
${ }^{1}$ Derived from individual additive stigma score based on 3 questions: whether respondent would care for a relative with AIDS; would buy vegetables from vendor with AIDS; and whether someone with AIDS should be allowed to continue teaching. Individual score ranges from 0 (no stigma) to maximum of 6 .

${ }^{2}$ Derived from individual awareness index based on 11 questions on misconceptions, mode of HIV transmission and ways to prevent infection. Individual additive score ranges from 0 (least knowledge) to a maximum of 11.

${ }^{3}$ World Bank (2017). "GDP per capita, PPP (current international \$)", World Development Indicators database (http://data.worldbank.org/indicator/NY.GDP.PCAP.PP.CD?locations=AO\&order=wbapi_data_valu e_2014+wbapi_data_value+wbapi_data_value-last\&sort=desc (Accessed 7 April 2017)
} 
Annex (ii): National contextual factors considered in the analysis

\begin{tabular}{|c|c|c|c|c|c|c|}
\hline Country & $\begin{array}{c}\text { Proportion } \\
\text { tested for HIV }\end{array}$ & $\begin{array}{l}\text { Mean HIV } \\
\text { stigma }\end{array}$ & $\begin{array}{c}\text { mean HIV } \\
\text { awareness }\end{array}$ & $\begin{array}{c}\text { HIV prevalence } \\
(\%)\end{array}$ & $\begin{array}{l}\text { Mean years } \\
\text { of education }\end{array}$ & $\begin{array}{l}\text { GDP per-capita } \\
\text { in US\$ ‘000's }\end{array}$ \\
\hline Burkina Faso (2010) & 0.32 & 2.30 & 7.40 & 1.2 & 1.82 & 1.30 \\
\hline Burundi (2010) & 0.82 & 1.43 & 8.40 & 1.7 & 3.61 & 0.69 \\
\hline Cameroon (2011) & 0.26 & 1.81 & 6.75 & 5.6 & 6.24 & 2.61 \\
\hline Congo-Brazzaville (2009) & 0.22 & 2.09 & 6.55 & 4.1 & 6.46 & 5.13 \\
\hline DR Congo (2013-14) & 0.18 & 2.64 & 6.12 & 1.6 & 5.71 & 0.70 \\
\hline Cote dlvoire (2011-12) & 0.37 & 1.92 & 6.37 & 4.6 & 3.09 & 2.55 \\
\hline Ethiopia (2011) & 0.42 & 2.21 & 6.46 & 1.9 & 3.29 & 1.17 \\
\hline Gabon (2012) & 0.65 & 1.31 & 7.54 & 5.8 & 7.13 & 17.92 \\
\hline Gambia (2013) & 0.42 & 2.38 & 7.18 & 2.1 & 4.30 & 1.65 \\
\hline Ghana (2014) & 0.47 & 2.82 & 6.86 & 2.8 & 6.81 & 4.10 \\
\hline Guinea (2012) & 0.11 & 3.82 & 6.39 & 2.1 & 2.55 & 1.22 \\
\hline Kenya (2008-09) & 0.59 & 1.34 & 7.70 & 8.0 & 7.42 & 2.30 \\
\hline Lesotho (2009) & 0.71 & 0.94 & 8.96 & 26.7 & 7.84 & 2.21 \\
\hline Liberia (2013) & 0.48 & 2.87 & 7.05 & 2.4 & 3.47 & 0.85 \\
\hline Malawi (2010) & 0.74 & 0.65 & 9.29 & 12.9 & 5.35 & 1.04 \\
\hline Mali (2012-13) & 0.16 & 2.02 & 6.63 & 1.4 & 2.00 & 1.83 \\
\hline Mozambique (2009) & 0.41 & 1.26 & 8.05 & 12.7 & 3.24 & 0.85 \\
\hline Namibia (2013) & 0.80 & 0.49 & 8.56 & 16.8 & 8.47 & 9.46 \\
\hline Niger (2012) & 0.29 & 3.08 & 6.17 & 0.4 & 1.70 & 0.88 \\
\hline Rwanda (2010) & 0.77 & 0.62 & 8.73 & 3.7 & 4.50 & 1.30 \\
\hline Sao Tome (2008-09) & 0.68 & 1.56 & 8.01 & 1.3 & 5.19 & 2.48 \\
\hline Senegal (2010-11) & 0.28 & 2.45 & 6.84 & 0.8 & 2.54 & 2.13 \\
\hline Siera Leone (2013) & 0.51 & 2.51 & 6.78 & 1.7 & 3.64 & 1.92 \\
\hline Swaziland (2006-07) & 0.41 & 0.80 & 9.46 & 31.1 & 8.08 & 6.55 \\
\hline Tanzania (2011-12) & 0.66 & 1.18 & 7.78 & 6.2 & 6.12 & 2.29 \\
\hline Togo (2013-14) & 0.49 & 2.08 & 7.18 & 3.1 & 4.34 & 1.34 \\
\hline Uganda (2011) & 0.68 & 1.10 & 7.77 & 8.2 & 5.44 & 1.67 \\
\hline Zambia (2013-14) & 0.81 & 0.81 & 9.02 & 15.1 & 6.97 & 3.68 \\
\hline Zimbabwe (2010-11) & 0.61 & 0.75 & 8.74 & 17.7 & 8.95 & 1.36 \\
\hline
\end{tabular}


Annex (iii): Correlation matrix for national contextual factors considered in the analysis

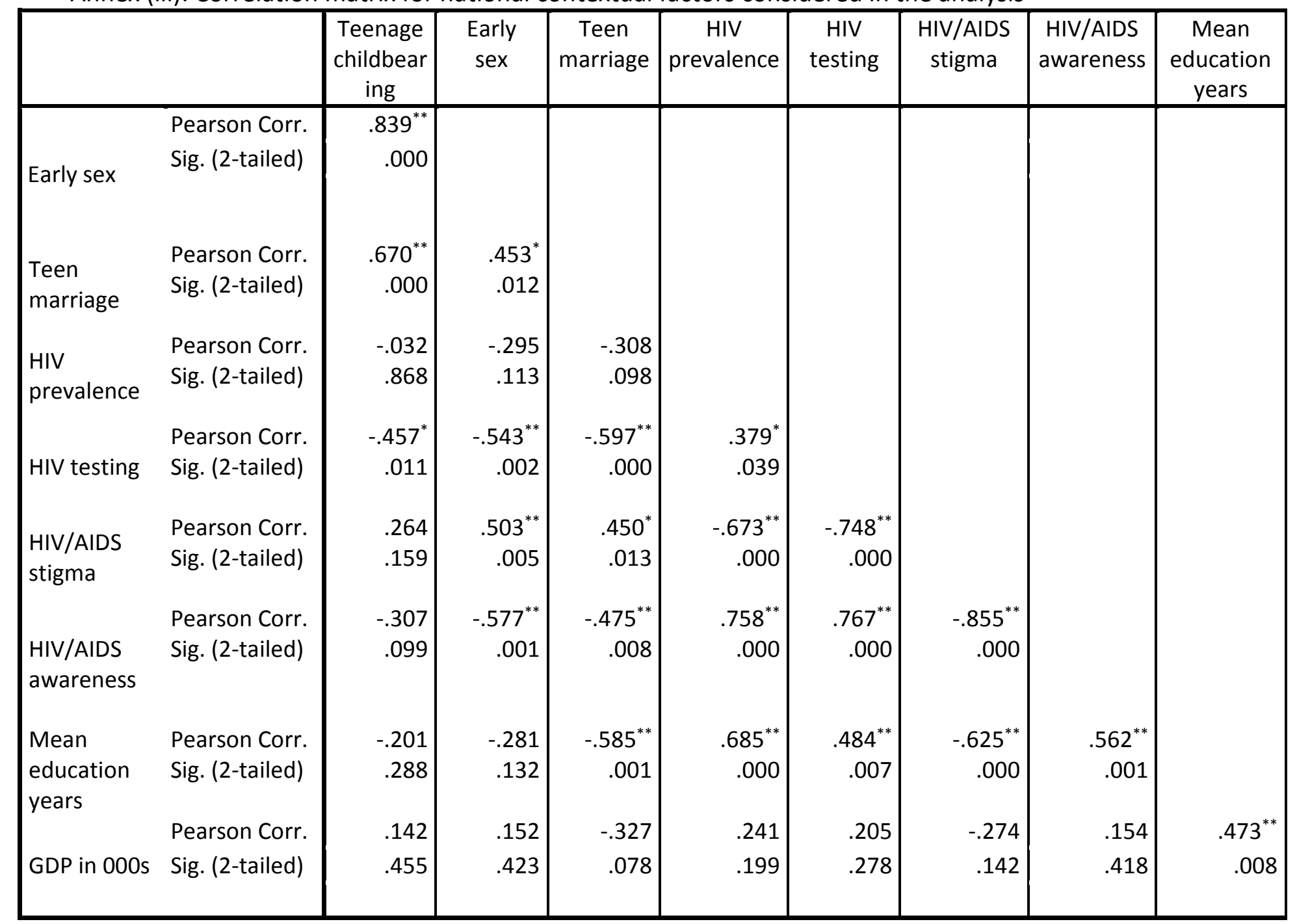


Annex iv: Unadjusted ${ }^{£}$ multilevel logistic regression parameter estimates (standard errors given in brackets) of the determinants of teenage childbearing across countries of SSA

\begin{tabular}{|c|c|c|c|}
\hline Parameter & Estimate & standard error & Sig. \\
\hline Intercept & -1.54 & 0.130 & \\
\hline Age in years & 0.83 & 0.009 & * \\
\hline Year of survey & 0.04 & 0.068 & \\
\hline \multicolumn{4}{|l|}{ Country-level factors } \\
\hline HIV prevalence $\$$ & 0.07 & 0.190 & \\
\hline HIV testing coverage $\mathrm{e}^{\$}$ & -0.15 & 0.055 & * \\
\hline HIV/AIDS stigma & 0.25 & 0.165 & \\
\hline HIV awareness & -0.24 & 0.143 & \\
\hline Female education & -0.05 & 0.062 & \\
\hline GDP in '000' & 0.03 & 0.037 & \\
\hline \multicolumn{4}{|l|}{ Cluster-level factors } \\
\hline HIV prevalence & -0.02 & 0.016 & \\
\hline HIV testing coverage & -0.11 & 0.008 & * \\
\hline HIV/AIDS stigma & 0.45 & 0.014 & * \\
\hline HIV awareness & -0.32 & 0.012 & * \\
\hline Female education & -0.26 & 0.006 & $*$ \\
\hline Average wealth & -0.48 & 0.011 & * \\
\hline \multicolumn{4}{|l|}{ Random Variance } \\
\hline Country & 0.48 & 0.127 & * \\
\hline Cluster & 0.72 & 0.026 & $*$ \\
\hline \multicolumn{4}{|c|}{ * significant at $5 \%$ level $-p<0.05$} \\
\hline \multicolumn{4}{|c|}{$\begin{array}{l}\$ \text { - measures re-scaled so that a unit is equivalent to } 10 \text { percentage points to ease interpretation } \\
f \text { - controlling only for individual age in single years and year of survey. }\end{array}$} \\
\hline
\end{tabular}

